\title{
Acquired resistance to immunotherapy in MMR-D pancreatic cancer
}

\author{
Zishuo lan Hu' ${ }^{1}$, Matthew D. Hellmann 1,2,3,4, Jedd D. Wolchok ${ }^{1,2,3,4}$, Monika Vyas ${ }^{1,5}$, Jinru Shia ${ }^{1,5,6}$, \\ Zsofia K. Stadler ${ }^{1,2,4}$, Luis A. Diaz Jr, $r^{1,2}$ and Eileen M. O'Reilly ${ }^{1,2,4,7^{*}}$
}

\begin{abstract}
Background: MMR-D pancreatic cancer have been reported to respond to checkpoint inhibitor therapy. Here, we report the first case of acquired resistance to immunotherapy in MMR-D pancreatic cancer.

Case presentation: A 45-year-old woman with unresectable MMR-D pancreatic cancer was initially treated with FOLFIRINOX, FOLFIRI, and stereotactic body radiation with stable disease burden. After 3 months, imaging showed progression of disease with an increase in CA19-9. She was subsequently enrolled in a clinical trial of an anti-PD-L1 antibody in combination with an IDO1 inhibitor. She demonstrated a partial response to therapy by RECIST 1.1 criteria with declining tumor markers. Twenty-two months after beginning immunotherapy, imaging revealed an increasing left ovarian cystic mass. There were no other sites of progressive disease. The patient underwent a total hysterectomy and bilateral salpingo-oophorectomy, appendectomy, omentectomy and pelvic lymphadenopathy. Pathology was consistent with a metastasis from the pancreas involving the endometrium and left ovary. Thereafter, the patient continued with PD-1 blockade therapy off protocol with no further progressive disease. Immune profiling showed high levels of CD8+ T cells and PD-1 positive immune cells infiltrating the tumor, with a moderate level of PDL1 expression in both the immune cells and the tumor cells. Next generation sequencing found only the KRAS G12D and RNF43 G659Vfs*41 mutations were retained from the pre-treatment tumor in the treatment-resistant tumor.
\end{abstract}

Conclusions: This is the first report describing acquired resistance to immunotherapy in MMR-D pancreatic cancer with accompanying genomic and immune profiling. This case of oligoprogression in the setting of immunotherapy demonstrates the feasibility of localized treatment followed by continuation of immunotherapy to sustain ongoing response.

Keywords: Pancreatic cancer, Acquired resistance, Immunotherapy, Mismatch repair deficiency

\section{Background}

As checkpoint inhibitors have now entered broad use for the treatment of solid tumors, an increasing number of patients who initially respond to immunotherapy have been identified to develop acquired resistance. Such reports have been described in individuals with melanoma, non-small cell lung cancer (NSCLC), uterine leiomyosarcoma, and mismatch repair deficient (MMR-D) colorectal cancer (CRC) patients [1-7].

Pancreatic ductal adenocarcinoma (PDAC) has been largely refractory to single and combination checkpoint

\footnotetext{
* Correspondence: oreillye@mskcc.org

'Department of Medicine, Memorial Sloan Kettering Cancer Center, New York, NY, USA

${ }^{2}$ Division of Solid Tumor Oncology, New York, NY, USA

Full list of author information is available at the end of the article
}

inhibitor therapy [8-10]. The tumor microenvironment of PDAC have been described to be largely immunosuppressive, with involvement of regulatory $\mathrm{T}$ cells, tumor-associated macrophages (TAMs), and myeloid-derived suppressive cells (MDSCs) [11-13]. Another contributing factor to PDAC's immunotherapy resistance may be PDAC's relatively low tumor mutation burden (TMB) and poor antigenicity, leading to impaired endogenous $\mathrm{T}$ cell response to the tumor [14]. TMB, in general, has been reported to have a significant correlation with objective response rate to $\mathrm{PD}-1$ inhibition [15]. However, a rare subset of PDAC patients with MMR-D has been reported to have partial and complete responses to immunotherapy $[1,14]$. MMR-D occurs at a frequency of $<1 \%$ of all PDAC patients and is typically associated with germline mutations in MMR genes, IHC loss of MMR expression, an 
elevated MSIsensor score, significantly prolonged survival times, and high TMB.

Here, we describe a patient with locally advanced MMR-D PDAC who had a partial response to checkpoint inhibitor therapy, but subsequently acquired resistance to therapy and developed a metastasis to the ovary. We evaluated tumor cell-intrinsic and extrinsic causes of acquired resistance in the metastatic tumor. We determined the tumor mutational profile before and after acquired resistance using next generation sequencing (NGS) and assessed PD-1, PD-L1, and CD8+ T cell levels in the immunotherapy-resistant tumor specimen.

\section{Case presentation}

\section{Clinical course}

An otherwise healthy 45-year-old woman with known Lynch syndrome (germline mutation in MLH1) presented in 2014 with abdominal bloating. Computed tomography (CT) showed a $4 \mathrm{~cm}$ pancreatic body mass encasing the portal vein, splenomesenteric confluence, and common hepatic artery with enlarged periportal lymph nodes present. Biopsy revealed pancreatic adenocarcinoma. The patient was deemed to have unresectable disease and treated with FOLFIRINOX (5-fluorouracil, folinic acid, irinotecan, oxaliplatin) and FOLFIRI with stable disease burden and declining tumor markers (Fig. 1). She also received stereotactic body radiation therapy (SBRT) 3300 cGy in five fractions.

In 2015, CT scan revealed progression of disease, along with a rise in CA19-9 and clinical symptoms. The patient was enrolled in a clinical trial (NCT 02471846) of an anti-PD-L1 antibody in combination with an IDO1 inhibitor (navoximod). She demonstrated a partial response as defined by RECIST 1.1 criteria with declining tumor markers and prompt resolution of symptoms. In 2017, 22 months after beginning therapy, CT scan revealed an increasing left ovarian cystic mass. There were no other sites of progressive disease. The patient underwent a total hysterectomy and bilateral salpingo-oophorectomy, appendectomy, omentectomy and pelvic lymphadenopathy. Pathology was consistent with a metastasis from the pancreas involving the endometrium and left ovary. Thereafter, the patient continued with PD-1 blockade therapy off protocol with no further progressive disease.

\section{Genomic features of pre-treatment and treatment- resistant tumors}

Tumor mutation profile and burden were determined through MSK-IMPACT, a next generation sequencing assay of somatic mutations in key cancer genes [16]. $\mathrm{TMB}$ was 50.2 mutations per megabase $(\mathrm{mt} / \mathrm{Mb})$ in the pretreatment sample and $21.1 \mathrm{mt} / \mathrm{Mb}$ in the acquired resistance sample (Table 1); both tumors were computationally consistent with microsatellite-instability high. Only the KRAS G12D and RNF43 G659Vfs*41 mutations were retained from the pre-treatment tumor in the treatment-resistant tumor. No copy number alterations were detected in either the pre-treatment or the acquired resistance tumor sample. There was no loss-of-function mutations or loss of heterozygosity (LOH) in the $H L A$ genes, B2M, PTEN, JAK1, JAK2, or TAP1.

\section{Pathological features of the treatment-resistant tumor} Immunohistochemistry (IHC) of the metastatic sample confirmed that the tumor was MMR-D, with loss of MLH1 and PMS2 expression (Fig. 2a-e). Histologically

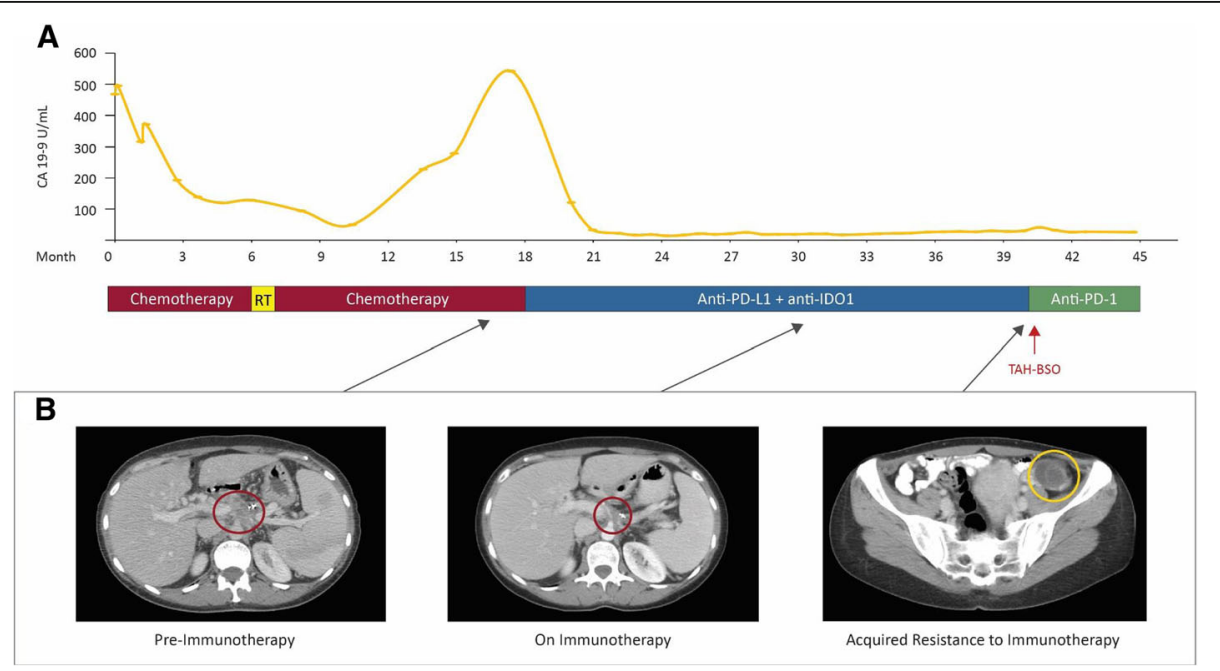

Fig. 1 Clinical Pattern of Acquired Resistance. Panel a shows CA 19-9 levels corresponding to the timeline showing therapy. Panel b shows axial CT images corresponding to the primary pancreatic mass before treatment with immunotherapy and during immunotherapy, and the ovarian mass that developed after 22 months of immunotherapy. Red circles indicate the pancreatic mass and the yellow circle indicates the ovarian mass. Panel $\mathbf{b}$ shows the pancreatic mass after chemotherapy and RT 
Table 1 Mutations in primary and metastatic lesions

\begin{tabular}{|c|c|}
\hline Gene & Protein chan \\
\hline \multicolumn{2}{|c|}{ Primary Pancreas Lesion } \\
\hline KRAS & G12D \\
\hline RNF43 & G659Vfs*41 \\
\hline ARIDIA & P1326Rfs*155 \\
\hline STK11 & P281Rfs*6 \\
\hline$B 2 M$ & $\mathrm{~S} 14 \mathrm{Ffs}^{*} 29$ \\
\hline MAP3K1 & N1079lfs*3 \\
\hline ARIDIA & A339Lfs*24 \\
\hline$C I C$ & P1529Lfs*91 \\
\hline ERCC4 & $\mathrm{R} 689 \mathrm{C}$ \\
\hline PIK3R1 & M1? \\
\hline KMT2A & $\mathrm{S} 2872^{*}$ \\
\hline BCL2L11 & $\mathrm{S} 118 \mathrm{KfS}^{*} 21$ \\
\hline MLH1 & X556_splice \\
\hline FANCA & P1444Rfs*3 \\
\hline$B R C A 2$ & R2502C \\
\hline$B C O R$ & S526L \\
\hline$B R C A 2$ & K1191 M \\
\hline ALK & G1202Efs*56 \\
\hline ZFHX3 & A3407Lfs*78 \\
\hline PTPRS & $\mathrm{R} 1102 \mathrm{H}$ \\
\hline FLT1 & $\mathrm{R} 1305 \mathrm{H}$ \\
\hline$A R$ & $\mathrm{R} 280 \mathrm{C}$ \\
\hline ROS1 & $\mathrm{R} 1592 \mathrm{C}$ \\
\hline$J A K 3$ & P84Rfs*63 \\
\hline PTPRT & I502T \\
\hline RECQL4 & V155Sfs*25 \\
\hline VTCN1 & $\mathrm{Y} 145 \mathrm{H}$ \\
\hline RAF1 & Y458F \\
\hline SETD2 & D1057N \\
\hline GATA2 & P385S \\
\hline$A P C$ & R259Q \\
\hline$A P C$ & T1932A \\
\hline$A R I D 1 B$ & G314R \\
\hline$A R I D 1 B$ & $\mathrm{~A} 1002 \mathrm{~V}$ \\
\hline RECQL4 & G1166S \\
\hline RECQL4 & A33V \\
\hline PAX5 & R38C \\
\hline TGFBR1 & V229D \\
\hline $\mathrm{H} 3 \mathrm{~F} 3 \mathrm{C}$ & M120V \\
\hline KMT2D & S1555F \\
\hline CREBBP & P2311L \\
\hline ZFHX3 & T2667A \\
\hline PLCG2 & L631R \\
\hline
\end{tabular}

Table 1 Mutations in primary and metastatic lesions (Continued)

\begin{tabular}{lll}
\hline Gene & Protein change & Mutation type \\
\hline SPOP & N196K & Missense_Mutation \\
STK11 & L285R & Missense_Mutation \\
INSR & R279H & Missense_Mutation \\
MEF2B & P106H & Missense_Mutation \\
TOP1 & 1457T & Missense_Mutation \\
NF2 & K469R & Missense_Mutation \\
AR & V139M & Missense_Mutation \\
TRAF7 & N174del & In_Frame_Del
\end{tabular}

Metastatic Site: Ovary/Endometrium

\begin{tabular}{|c|c|c|}
\hline KRAS & G12D & Missense_Mutation \\
\hline RNF43 & G659Vfs*41 & Frame_Shift_Del \\
\hline TSC2 & Q35* & Nonsense_Mutation \\
\hline TP53 & R273C & Missense_Mutation \\
\hline STK11 & X245_splice & Splice_Site \\
\hline PBRM1 & P1411Lfs*21 & Frame_Shift_Del \\
\hline BARD1 & $\mathrm{K} 208 \mathrm{Rfs}^{*} 4$ & Frame_Shift_Del \\
\hline ATRX & D1940lfs*15 & Frame_Shift_Del \\
\hline KMT2D & K4318Efs*15 & Frame_Shift_Del \\
\hline KMT2B & G1879Vfs*16 & Frame_Shift_Del \\
\hline NRAS & A66V & Missense_Mutation \\
\hline $\mathrm{CIC}$ & $\mathrm{R} 440 \mathrm{H}$ & Missense_Mutation \\
\hline INSR & R1331C & Missense_Mutation \\
\hline MYCN & $\mathrm{R} 285 \mathrm{Q}$ & Missense_Mutation \\
\hline$B C L 6$ & S434 N & Missense_Mutation \\
\hline TNFAIP3 & K759Qfs*10 & Frame_Shift_Ins \\
\hline RPS6KA4 & RPS6KA4-BAD fusion & Fusion \\
\hline FLT3 & S188R & Missense_Mutation \\
\hline ERBB2 & $\mathrm{H} 193 \mathrm{~N}$ & Missense_Mutation \\
\hline DOT1L & V170 L & Missense_Mutation \\
\hline PTPRT & E917V & Missense_Mutation \\
\hline HIST1H3F & $\mathrm{T} 119 \mathrm{~A}$ & Missense_Mutation \\
\hline INHBA & $\mathrm{A} 41 \mathrm{~T}$ & Missense_Mutation \\
\hline$R X R A$ & $\mathrm{G} 73 \mathrm{C}$ & Missense_Mutation \\
\hline ARAF & E556G & Missense_Mutation \\
\hline$B A D$ & RPS6KA4-BAD fusion & Fusion \\
\hline
\end{tabular}

and immunophenotypically, the tumor exhibited features consistent with a metastasis of pancreatic origin including negative IHC staining for PAX8 (Fig. 2f), a marker typically associated with a Mullerian primary.

We were unable to assess immune cell infiltration with IHC in the pre-treatment tumor due to insufficient tissue. However, for the resected treatment-resistant metastasis, we found high levels of CD8+ T cells and PD-1 positive immune cells, with a moderate level of PD-L1 expression in both the immune cells and the tumor cells (Fig. 2g-i). 

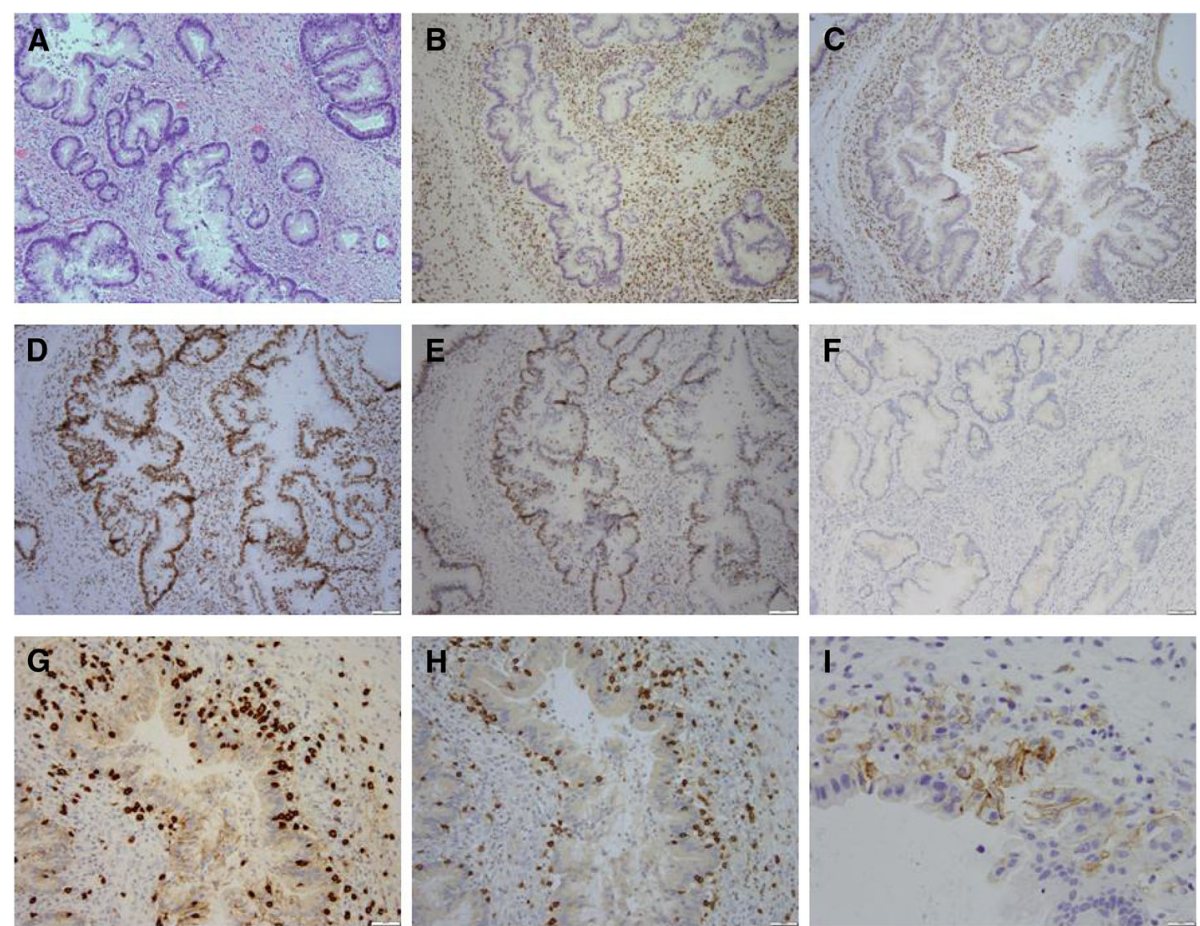

Fig. 2 Immune Profiling of Metastatic Lesion. Metastatic pancreatic adenocarcinoma showing loss of MLH1 and PMS2 and increased immune cell infiltration. H\&E section demonstrates a gland forming adenocarcinoma, morphologically compatible with pancreatic origin (a). By immunohistochemistry, the tumor cells show loss of staining for MLH1 (b) and PMS2 (c) and retained staining for MSH2 (d) and MSH6 (e). The tumor cells are also negative for PAX8 (f), in keeping with its non-Mullerian origin. Assessment of immune cell infiltration demonstrates florid CD8 positive T cells infiltrating the tumor epithelium and in the stroma surrounding the tumor epithelium (g). There is also prominent PD-1 positive immune cells (h) distributed similarly as the CD8 positive cells. PD-L1 expression is focally present in immune cells and in some tumor cells (i)

\section{Discussion}

Patients treated with immunotherapy may respond durably, fail to respond, or initially respond but subsequently develop acquired resistance. Acquired resistance to immunotherapy is a consequence of a number of tumor-extrinsic and tumor cell-intrinsic factors [17]. Tumor-extrinsic acquired resistance can be due to insufficient CD8 + T cell infiltration at the tumor microenvironment (TME) and immunosuppression in the TME by regulatory T cells, MDSCs, and TAMs [18]. Mechanisms of tumor-intrinsic acquired resistance include decreases in and loss of neoantigens [2, 4, 19], disruption of neoantigen presentation $[3,5,20,21]$, and resistance to interferon gamma [5].

The ovaries have been previously reported as a potential sanctuary site for malignant gastrointestinal metastases given their resistance to chemotherapy [22]. In this case, however, we did not see a deficit in immune cell infiltration at the ovarian site. Given the abundant CD8+ $\mathrm{T}$ cell infiltration, PD-1, and PD-L1 expression in the ovarian site, we speculate that the resistance mechanism is driven less by tumor-extrinsic factors and more by tumor-intrinsic factors.
In this case of acquired resistance to PDAC, the decrease in tumor mutation burden after treatment is likely reflective of immunoediting [23-25]. However, the robust $\mathrm{T}$ cell infiltration within the resistant tumor microenvironment suggests a potential alternate mechanism restraining productive anti-tumor immunity. Through genomic profiling, we found no changes in loss of function or loss of heterozygosity in previously reported mechanisms of intrinsic resistance, including the $H L A$ genes, B2M, PTEN, JAK1, JAK2, or TAP1. Similar cases in which the driver of resistance is unknown have been reported, and highlight the complexity of resistance in the context of immunotherapy and the need for larger, cooperative efforts to integrate analyses of these uncommon cases in order to reveal mechanistic insight [26].

In this PDAC patient, disease progression only occurred in the ovary, an uncommon site of metastases in PDAC [27]. The phenomenon and management of oligoprogression in the setting of acquired resistance to targeted therapy have been previously described in NSCLC [28]. But oligoprogression in the setting of acquired resistance to immunotherapy is less well described. A case series of acquired resistance to PD-1 axis inhibitors in 
26 NSCLC patients found that a majority (89\%) of these patients had recurrence limited to one or two sites of disease [7]. Isolated progression was also reported in the majority (78\%) of 36 melanoma patients with acquired resistance to PD-1 blockade [29]. MMR-D patients under PD-1 blockade have been reported to develop acquired resistance, with tumors developing from occult sites such as the brain and the bone [1].

The present report has notable limitations. No clear mechanism of resistance was determined, although we speculate that immunoediting is a primary driving mechanism. Immunoediting is a dynamic dialogue between the immune system and the invading system that consists of elimination, equilibrium, and escape phases [30]. In the elimination phase, tumor cells are identified and eliminated by the immune system. In the equilibrium phase, the immune system is unable to eliminate all cancer cells but is able to contain further growth. In the escape phase, tumor cells variants are selected to proliferate in an immunologically intact environment. Genetic and epigenetic changes within these tumor cells grant additional resistance to immune elimination, allowing the tumor cells to grow. Further in vitro studies are needed to determine the specific acquired changes within the tumor and the selection pressure exerted by PD-L1 therapy. We also had insufficient pre-treatment tissue for immunopathologic testing to directly compare the phenotypic changes.

This is the first reported case, to our knowledge, of acquired immunotherapy resistance in PDAC with accompanying genomic and immune profiling of the metastasis. This case of oligoprogression in the setting of immunotherapy also highlights the feasibility of localized treatment followed by continuation of immunotherapy to sustain ongoing response elsewhere. A number of factors, including tumor heterogeneity, the specific resistance mechanism, and tissue-specific immunoregulation, likely influence the sites, extent, and rate of disease progression in acquired resistance to immunotherapy, and remain to be fully characterized [31].

\section{Abbreviations \\ CRC: Colorectal cancer; CT: Computed tomography; IHC: Immunohistochemistry; LOH: Loss of heterozygosity; MDSC: Myeloid-derived suppressive cell; MMR- D: Mismatch repair deficient; NGS: Next generation sequencing; NSCLC: Non-small cell lung cancer; PDAC: Pancreatic ductal adenocarcinoma; SBRT: Stereotactic body radiation; TAM: Tumor-associated macrophages; TMB: Tumor mutation burden; TME: Tumor microenvironment; T-regs: T-regulatory cells}

\section{Acknowledgments}

The authors wish to gratefully acknowledge the patient and her family for allowing us to publish her case report.

\section{Funding}

This work was supported in part by the National Cancer Institute Cancer Center Core Grant No. P30-17 CA008748.
Availability of data and materials

The datasets used and/or analyzed during the current study are available from the corresponding author on reasonable request.

\section{Authors' contributions}

All authors were involved in the generation of figures and writing of the manuscript. All authors read and approved the final manuscript.

Ethics approval and consent to participate

The patient described in this case signed a case report informed consent form which is available for review.

\section{Consent for publication}

The patient consented to publication of the case report. Informed written consent was obtained from patient for publication of this case. Consent is available upon request.

\section{Competing interests}

Eileen M. O'Reilly (EOR): Research Funding Celgene, Sanofi, ActaBiologica, AstraZenica, Silenseed, Genentech-Roche. Consulting: Targovax, Celgene, Bayer. Matthew D. Hellman (MDH) receives research funding from BristolMyers Squibb; is paid consultant to Merck, Bristol-Myers Squibb, AztraZeneca, Genentech/Roche, Janssen, Nektar, Syndax, Mirati, and Shattuck Labs; receives travel support/honoraria from AztraZeneca and BMS; and a patent has been filed by MSK related to the use of tumor mutation burden to predict response to immunotherapy (PCT/US2015/062208), which has received licensing fees from PGDx.Luis A. Diaz (LAD) is a member of the board of directors of Personal Genome Diagnostics (PGDx) and Jounce Therapeutics. LAD holds equity in PapGene, Personal Genome Diagnostics (PGDx) and Phoremost. He is a paid consultant for Merck, PGDx and Phoremost. LAD is an inventor of licensed intellectual property related to technology for circulating tumor DNA analyses and mismatch repair deficiency for diagnosis and therapy (WO2016077553A1) from Johns Hopkins University. These licenses and relationships are associated with equity or royalty payments to LAD. The terms of all these arrangements are being managed by Johns Hopkins and Memorial Sloan Kettering in accordance with their conflict of interest policies. In addition, in the past 5 years, LAD has participated as a paid consultant for one-time engagements with Caris, Lyndra, Genocea Biosciences, Illumina and Cell Design Labs. Jedd Wochok (JD) Consultant for: Adaptive Biotech; Advaxis; Amgen; Apricity; Array BioPharma; Ascentage Pharma;Astellas; Beigene; Bristol Myers Squibb; Celgene; Chugai; Elucida; Eli Lilly; F Star; Genentech; Imvaq; Kleo Pharma; Medlmmune; Merck; Neon Therapuetics; Ono; Polaris Pharma; Polynoma; Psioxus; Puretech; Recepta; Trieza; Sellas Life Sciences; Serametrix; Surface Oncology; Syndax. Research support: Bristol Myers Squibb; Medimmune; Merck Pharmaceuticals; Genentech. Equity in: Potenza Therapeutics; Tizona Pharmaceuticals; Adaptive Biotechnologies; Elucida; Imvaq; Beigene; Trieza.Zsofia Stadler (ZK): Immediate Family Member, Ophthalmology Consulting/Advisory Role: Allergan, Adverum Biotechnologies, Alimera Sciences, Biomarin, Fortress Biotech, Genentech, Novartis, Optos, Regeneron, Regenxbio, Spark Therapeutics. The other authors (ZIH, MV, JS) declare that they have no competing interests.

\section{Publisher's Note}

Springer Nature remains neutral with regard to jurisdictional claims in published maps and institutional affiliations.

\section{Author details}

'Department of Medicine, Memorial Sloan Kettering Cancer Center, New York, NY, USA. ${ }^{2}$ Division of Solid Tumor Oncology, New York, NY, USA. ${ }^{3}$ Parker Institute for Cancer Immunotherapy at Memorial Sloan Kettering, New York, NY, USA. ${ }^{4}$ Department of Medicine, Weill Cornell Medical College, New York, NY, USA. ${ }^{5}$ Department of Pathology, Memorial Sloan Kettering Cancer Center, New York, USA. 'D Department of Pathology, Weill Cornell Medical College, New York, NY, USA. ${ }^{7}$ David M. Rubenstein Center for Pancreatic Cancer Research, New York, NY, USA. 
Received: 5 September 2018 Accepted: 8 November 2018

Published online: 20 November 2018

\section{References}

1. Le DT, Durham JN, Smith KN, Wang H, Bartlett BR, Aulakh LK, et al. Mismatch repair deficiency predicts response of solid tumors to PD-1 blockade. Science. 2017:357(6349):409-13.

2. Anagnostou V, Smith KN, Forde PM, Niknafs N, Bhattacharya R, White J, et al. Evolution of neoantigen landscape during immune checkpoint blockade in non-small cell lung cancer. Cancer Discov. 2017;7(3):264-76.

3. Gettinger S, Choi J, Hastings K, Truini A, Datar I, Sowell R, et al. Impaired HLA class I antigen processing and presentation as a mechanism of acquired resistance to immune checkpoint inhibitors in lung cancer. Cancer Discov. 2017;7(12):1420-35.

4. George S, Miao D, Demetri GD, Adeegbe D, Rodig SJ, Shukla S, et al. Loss of PTEN is associated with resistance to anti-PD-1 checkpoint blockade therapy in metastatic uterine leiomyosarcoma. Immunity. 2017;46(2):197-204.

5. Zaretsky JM, Garcia-Diaz A, Shin DS, Escuin-Ordinas H, Hugo W, HuLieskovan S, et al. Mutations associated with acquired resistance to PD-1 blockade in melanoma. N Engl J Med. 2016;375(9):819-29.

6. Chang CC, Campoli M, Restifo NP, Wang X, Ferrone S. Immune selection of hot-spot beta 2-microglobulin gene mutations, HLA-A2 allospecificity loss, and antigen-processing machinery component down-regulation in melanoma cells derived from recurrent metastases following immunotherapy. J Immunol. 2005:174(3):1462-71.

7. Gettinger SN, Wurtz A, Goldberg SB, Rimm D, Schalper K, Kaech S, et al. Clinical features and management of acquired resistance to PD-1 axis inhibitors in twentysix patients with advanced non-small cell lung cancer. J Thorac Oncol. 2018;13(6): 831-9. https://doi.org/10.1016/j.jtho.2018.03.008. Epub 2018 Mar 22.

8. Royal RE, Levy C, Turner K, Mathur A, Hughes M, Kammula US, et al. Phase 2 trial of single agent Ipilimumab (anti-CTLA-4) for locally advanced or metastatic pancreatic adenocarcinoma. J Immunother. 2010;33(8):828-33.

9. Brahmer JR, Tykodi SS, Chow LQ, Hwu WJ, Topalian SL, Hwu P, et al. Safety and activity of anti-PD-L1 antibody in patients with advanced cancer. N Engl J Med. 2012;366(26):2455-65.

10. O'Reilly EM, Oh D-Y, Dhani N, Renouf DJ, Lee MA, Sun W, et al. A randomized phase 2 study of durvalumab monotherapy and in combination with tremelimumab in patients with metastatic pancreatic ductal adenocarcinoma (mPDAC): ALPS study. J Clin Oncol. 2018;36(4_ suppl):217.

11. Hiraoka N, Onozato K, Kosuge T, Hirohashi S. Prevalence of FOXP3+ regulatory $T$ cells increases during the progression of pancreatic ductal adenocarcinoma and its premalignant lesions. Clin Cancer Res. 2006;12(18): 5423-34.

12. Porembka MR, Mitchem JB, Belt BA, Hsieh CS, Lee HM, Herndon J, et al. Pancreatic adenocarcinoma induces bone marrow mobilization of myeloidderived suppressor cells which promote primary tumor growth. Cancer Immunol Immunother. 2012;61(9):1373-85.

13. Mitchem JB, Brennan DJ, Knolhoff BL, Belt BA, Zhu Y, Sanford DE, et al. Targeting tumor-infiltrating macrophages decreases tumor-initiating cells, relieves immunosuppression, and improves chemotherapeutic responses. Cancer Res. 2013;73(3):1128-41

14. Hu ZI, Shia J, Stadler ZK, Varghese AM, Capanu M, Salo-Mullen E, et al. Evaluating mismatch repair deficiency in pancreatic adenocarcinoma: challenges and recommendations. Clin Cancer Res. 2018;24(6):1326-36.

15. Yarchoan M, Hopkins A, Jaffee EM. Tumor mutational burden and response rate to PD-1 inhibition. N Engl J Med. 2017;377(25):2500-1.

16. Cheng DT, Mitchell TN, Zehir A, Shah RH, Benayed R, Syed A, et al. Memorial Sloan Kettering-integrated mutation profiling of actionable cancer targets (MSKIMPACT): a hybridization capture-based next-generation sequencing clinical assay for solid tumor molecular oncology. J Mol Diagn. 2015;17(3):251-64.

17. Sharma P, Hu-Lieskovan S, Wargo JA, Ribas A. Primary, adaptive, and acquired resistance to cancer immunotherapy. Cell. 2017;168(4):707-23.

18. Wachsmann MB, Pop LM, Vitetta ES. Pancreatic ductal adenocarcinoma: a review of immunologic aspects. J Investig Med. 2012;60(4):643-63.

19. Tran E, Robbins PF, Lu YC, Prickett TD, Gartner JJ, Jia L, et al. T-cell transfer therapy targeting mutant KRAS in cancer. N Engl J Med. 2016;375(23):2255-62.

20. Restifo NP, Marincola FM, Kawakami Y, Taubenberger J, Yannelli JR, Rosenberg SA. Loss of functional beta 2-microglobulin in metastatic melanomas from five patients receiving immunotherapy. J Natl Cancer Inst. 1996;88(2):100-8.
21. Donia M, Harbst $K$, van Buuren M, Kvistborg P, Lindberg MF, Andersen $R$, et al. Acquired immune resistance follows complete tumor regression without loss of target antigens or IFNgamma signaling. Cancer Res. 2017;77(17): 4562-6.

22. Taylor AE, Nicolson VM, Cunningham D. Ovarian metastases from primary gastrointestinal malignancies: the Royal Marsden Hospital experience and implications for adjuvant treatment. Br J Cancer. 1995;71(1):92-6.

23. Riaz N, Havel JJ, Makarov V, Desrichard A, Urba WJ, Sims JS, et al. Tumor and microenvironment evolution during immunotherapy with nivolumab. Cell. 2017;171(4):934-49 e15.

24. Shankaran V, Ikeda $H$, Bruce AT, White JM, Swanson PE, Old $\sqcup$, et al. IFNgamma and lymphocytes prevent primary tumour development and shape tumour immunogenicity. Nature. 2001:410(6832):1107-11.

25. Dunn GP, Bruce AT, Ikeda H, Old LJ, Schreiber RD. Cancer immunoediting: from immunosurveillance to tumor escape. Nat Immunol. 2002:3(11):991-8.

26. Ascierto ML, Makohon-Moore A, Lipson EJ, Taube JM, McMiller TL, Berger $A E$, et al. Transcriptional mechanisms of resistance to anti-PD-1 therapy. Clin Cancer Res. 2017;23(12):3168-80.

27. Yachida S, lacobuzio-Donahue CA. The pathology and genetics of metastatic pancreatic cancer. Arch Pathol Lab Med. 2009;133(3):413-22.

28. Gandara DR, Li T, Lara PN, Kelly K, Riess JW, Redman MW, et al. Acquired resistance to targeted therapies against oncogene-driven non-small-cell lung cancer: approach to subtyping progressive disease and clinical implications. Clin Lung Cancer. 2014;15(1):1-6.

29. Wang DY, Eroglu Z, Ozgun A, Leger PD, Zhao S, Ye F, et al. Clinical features of acquired resistance to anti-PD-1 therapy in advanced melanoma. Cancer Immunol Res. 2017:5(5):357-62.

30. Dunn GP, Old $L$, Schreiber RD. The three Es of cancer immunoediting. Annu Rev Immunol. 2004;22:329-60.

31. Pao W, Ooi CH, Birzele F, Ruefli-Brasse A, Cannarile MA, Reis B, et al. Tissuespecific immunoregulation: a call for better understanding of the "immunostat" in the context of cancer. Cancer Discov. 2018;8(4):395-402.

Ready to submit your research? Choose BMC and benefit from:

- fast, convenient online submission

- thorough peer review by experienced researchers in your field

- rapid publication on acceptance

- support for research data, including large and complex data types

- gold Open Access which fosters wider collaboration and increased citations

- maximum visibility for your research: over $100 \mathrm{M}$ website views per year

At $\mathrm{BMC}$, research is always in progress.

Learn more biomedcentral.com/submissions 